\title{
Folhetos de cordel e a poesia popular
}

Arlindo Rebechi Junior

Docente do Departamento de Ciências Humanas da Faculdade de Arquitetura, Artes e Comunicação (FAAC) da Universidade Estadual Paulista (Unesp), atuando em diversos cursos na graduação e no Programa de Pós-Graduação em Comunicação.

E-mail: arlindo.rebechi@unesp.br

Resumo: Este artigo é uma apresentação e contextualização da poesia popular de folhetos, conhecida também como folhetos de cordel. Os folhetos surgem, como registro escrito e prática editorial, em fins do século XIX. Sua gênese está ligada à prática de uma poesia oral cantada em diversos espaços públicos e privados no Nordeste brasileiro, marca que carrega até os dias atuais. Na parte final do artigo, foram abordados os trabalhos de três relevantes poetas da primeira geração de autores brasileiros: Silvino Pirauá de Lima (1848-1913), Leandro Gomes de Barros (1865-1918) e João Melquíades Ferreira da Silva (1869-1933).

Palavras-chave: poesia popular brasileira; folheto; cordel; literatura brasileira.
Abstract: This article presents and contextualizes popular poetry of chapbooks, also known as folhetos in Brazil. This poetry is a written record and editorial practice from late nineteenth century. Its origins are related to the practice of poetry sung in various public and private spaces in the Northeast region of Brazil, a characteristic that is still present today. In the final part of this article, the works of three relevant poets of the first generation of Brazilian authors were approached: Silvino Pirauá de Lima (1848-1913), Leandro Gomes de Barros (1865-1918) and João Melquíades Ferreira da Silva (1869-1933).

Keywords: brazilian popular poetry; folheto; brazilian literature. 
comunicação \& educação • Ano XXV • número 1 • jan/jun 2020

Se entrega, Corisco! Eu não me entrego não, Eu não sou passarinho Pra viver lá na prisão!

Se entrega, Corisco!

Eu não me entrego não! Não me entrego ao tenente, Não me entrego ao capitão, Eu me entrego só na morte,

De parabelo na mão!

Canção de Glauber Rocha e Sérgio Ricardo presente no filme Deus e o Diabo na Terra do Sol $(1964)^{1}$

\section{A POESIA DE FOLHETO E A TRADIÇÃO ORAL}

Antonio Candido, em seu célebre texto, "A literatura e a formação do homem", nos chama a atenção sobre o papel da literatura na constituição das personalidades de todos os indivíduos de uma sociedade. Entendida de maneira ampla pelo crítico - desde as formas de expressão advindas da tradição oral até as formas mais complexas de registro verbal-escrito de uma cultura letrada canônica -, a literatura na vida social tornou-se uma necessidade de todos os seres humanos, sem exceção. Socialmente, a ausência da fruição literária poderia significar o risco ao caos interno ou a mutilação do próprio sujeito ${ }^{2}$.

Desde há muito tempo, essa ampla literatura, demandada em todos os cantos e por todas as pessoas, também se ligou às tradições orais de contar histórias. Neste contexto, em várias partes do mundo surgem registros dessa tradição literária, em especial na forma de versos. Se na França tem-se uma literatura de colportage, na Espanha, a pliego suelto, na Inglaterra, a chapbook ou as ditas baladas, no Brasil e em Portugal essa literatura ligada às tradições orais ficou conhecida como literatura de cordel $^{3}$. Em nosso caso, ficou muito mais conhecida como literatura de folhetos ou simplesmente como folhetos.

Sem dúvida, em terras brasileiras a literatura de folhetos de cordel esta-

1.Cf. ROCHA, Glauber. Deus e o Diabo na Terra do Sol. Rio de Janeiro: Editora Civilização Brasileira, 1965. p. 113.

2.CANDIDO, Antonio. A literatura e a formação do homem. In: CANDIDO Antonio. Textos de intervenção. Apresentações e notas de Vinicius Dantas. São Paulo: Duas Cidades: Editora 34. p. 77-92.

3.MEYER, Marlyse. Muitas histórias, muita poesia... In: MEYER, Marlyse (org.). Autores de cordel. São Paulo: Abril Educação, 1980. p. 3. beleceu suas principais características aclimatando-se ao universo cultural e social nordestino. Muitas hipóteses em torno de sua origem foram formuladas. Algumas delas, por sinal, mal desenvolvidas: é o caso da hipótese que vincula, estritamente, a origem da literatura de cordel brasileira à matriz europeia. Em estudo de referência sobre as produções de literatura de cordel portuguesa e as produções brasileiras do Nordeste, Márcia Abreu apontou sobre a impossibilidade de vínculo entre as duas formas literárias, no sentido de a europeia ser a matriz e a nacional ser a sua reprodução. Seu principal argumento é que a origem dessa visão, que vinculava a forma brasileira à europeia, está assentada na relação colonial estabelecida entre Portugal e Brasil. Abreu relata que

o imaginário das elites ocidentais construiu o "mito do colonizador" como ser culturalmente superior a quem cabe oferecer aos colonizados uma língua, uma 
religião, uma literatura, uma maneira de ver, pensar e organizar o mundo. O colonizado, culturalmente vazio, só teria a receber e nada a ofertar ${ }^{4}$.

É mais certeiro dizer que a gênese da literatura de cordel esteve atrelada às apresentações orais de poemas. Conhecidas como espetáculos de cantorias, tais apresentações poderiam acontecer em diversos espaços da vida pública e privada. Cantadores perambulavam por engenhos, casas-grandes e feiras, bem como também podiam se apresentar em mercados públicos, em festividades públicas que ocorriam em ruas e praças ou em festas privadas que podiam acontecer nas casas de localidades urbanas. De acordo com Márcia Abreu, era bastante comum entre as formas desse espetáculo os desafios ou pelejas, que

são debates poéticos em que dois cantadores enfrentam-se, devendo dar prosseguimento aos versos apresentados pelo oponente, sem se retardar na composição de sua fala. A disputa encerra-se quando um dos antagonistas declara-se incapaz de prosseguir ou, simplesmente, para de cantar por não encontrar resposta adequada ${ }^{5}$.

A tradição oral dos cantadores criou uma conjuntura específica para o desenvolvimento e a difusão da poesia popular por muitas partes do sertão nordestino. Especial contribuição veio da região da Serra do Teixeira, no sertão paraibano. De lá, vem Agostinho Nunes da Costa, a quem se atribui a fundação dessa tradição de cantadores.

Depois de Agostinho, outros nomes contribuíram com o desenvolvimento dessa poesia no século XIX. Convém destacar o trabalho do poeta Silvino Pirauá de Lima ${ }^{6}$, em fins do século XIX. Este poeta, conforme a crítica já sublinhou sua importância, teve um papel de pioneirismo e foi o responsável por importantes aspectos de inovação na forma do verso, introduzindo a sextilha, com a construção de estrofes de seis versos em substituição à forma mais comum até então, de quadras com estrofes de quatro versos. Como nos desafios entre dois cantadores havia a obrigação de um deles responder as provocações do outro pelejador em uma quadra apenas, é de se supor, devido a tamanha complicação, que os cantadores sentissem a necessidade de ampliar o número de versos para que, assim, pudessem desenvolver seus tópicos de maneira mais livre. Deve-se ainda a Pirauá a introdução nas pelejas da "obrigação do adversário de compor o primeiro verso da resposta rimando com o último deixado pelo contendor - a regra da deixa"

Demarcado pela presença da oralidade e, portanto, pela cultura da memória, a regularidade dos padrões dessa forma de poesia popular torna-se central para a sua conservação, difusão e reconhecimento do público. Esta busca por um padrão de versificação mais compatível com o universo específico de recepção em que a poesia de folheto se insere, resultou em formas distintas de uso do verso. Sobre esses aspectos, Márcia Abreu sintetiza o seguinte:

Embora tenha havido um período em que conviveram múltiplas formas, em que quadras e sextilhas disputavam primazia, autores e público elegeram as sextilhas setessilábicas com rimas ABCBDB como forma predominante. No início do século XX, as quadras haviam desaparecido completamente das formas estróficas possíveis nas cantorias.

4.ABREU, Márcia. Histórias de cordéis e folhetos. Campinas: Mercado de Letras, 1999. p. 125.

5.Ibidem, p. 73-74. 6.Ver: MEYER, op. cit., p. 8; ABREU, op. cit., p. 84 7.ABREU, op. cit., p. 84. 


\begin{abstract}
Outras formas - sempre fixas - foram sendo incorporadas. Dentre elas, a de maior aceitação, tanto em pelejas quanto em narrativas, foi a estrofe de sete versos setessilábicos com rimas ABCBDDB. Nos desafios, como recursos para exibição da destreza poética ou como tentativa de dificultar a resposta do oponente, surgiram o martelo (décima em redondilhas menores), o galope a beira-mar (décimas em decassílabos, cujo último verso deveria terminar em 'beira-mar'), a gemedeira (sextilhas setessilábicas com um 'ai, ai, ui, ui', introduzido entre o quinto e o sexto versos) ${ }^{8}$.
\end{abstract}

\section{O FORMATO DA POESIA POPULAR DE FOLHETOS DE CORDEL}

Se a poesia popular nordestina se gestou e se firmou por meio de uma cultura oral, cujas pelejas e performances entre poetas-cantadores tem papel central, o registro escrito e impresso deu um novo impulso a essa forma poética.

O formato impresso dos folhetos de poesia popular permitiu aos poetas viverem do próprio ofício com as vendas. O comércio de folhetos era realizado, em grande parte, pelos próprios autores, que percorriam diferentes lugares, de tal sorte que ainda lhes eram permitidas, além das vendas, as apresentações da forma oral dessa mesma poesia. Além disto, não era incomum que, junto aos folhetos de poesia, outras mercadorias fossem também comercializadas.

Ainda que o formato impresso ganhasse maior notoriedade com essa nova forma de difusão, a forma popular das apresentações orais mantinha um forte e íntimo vínculo entre autor e público. Sua manutenção continuava a existir em concomitância à difusão dos folhetos. Sob o olhar do autor, era preciso realizar a manutenção de uma forma poética facilmente reconhecível e memorizável por um público que notava na forma oral da poesia um modelo muito bem realizado esteticamente. Isso explica, por exemplo, que, nos anos finais do século XIX e nos anos iniciais do século XX, os principais poeta de folhetos seguiram temas e normas formais mais ou menos rígidas em suas produções, de modo que pudessem, pela recepção do público, ser facilmente reconhecidos como poetas populares. Por sua vez, sob o ponto de vista do público, havia a procura por uma forma bastante difundida, cuja base poderia ser facilmente memorizada.

Ao distinguir a obra literária daquela que se produz sob o crivo ainda folclórico, Jerusa Pires Ferreira, em seu clássico livro Cavalaria em cordel, escreveu o seguinte:

Ao analisar o texto-cordel, sabe-se estar diante de uma criatura que tem a ver com determinados processos de folk, percebendo-se que a sua complexa mecânica de criação está relacionada com um grupo que aceita ou sanciona, atenta para uma certa censura preventiva da comunidade, e, de certo modo, atinge-se o alcance e uma produção, em parte sob o comando. Apropria-se ou rejeita-se da matriz ou do repertório consagrado, consoante uma série de condições de

vária ordem, intrínsecas ou extrínsecas, impostas pelo grupo a que se destina, 8.lbidem, p. 89, grifos da autora. 
pela cosmovisão do narrador e pelos seus próprios requisitos de poeta, em seu intuitivo e mágico ofício de poetar ${ }^{9}$.

Os temas presentes nos folhetos de cordel são os mais variados possíveis. Há o trabalho com temas mais tradicionais: o amor, o desencontro amoroso; as histórias de animais, bois, lagartixas, cabras, entre outros bichos; e a nobreza com príncipes, cavalheiros e guerreiros. Os folhetos também sempre estiveram muito suscetíveis aos temas do cotidiano; nesse quesito, a lista é infindável: crimes (locais, regionais e nacionais); desastres naturais (secas, enchentes etc.); tragédias de localidades próximas ou longínquas ou ainda movimentações sociais de forte apelo ao imaginário popular, tais como o Cangaço e a Guerra de Canudos.

Em termos da estrutura formal, como já se colocou antes, os folhetos quase sempre trabalham com a forma da sextilha, com estrofes de seis versos. Todavia, esse formato, a depender do poeta, pode ter variações. Vejamos o exemplo de uma estrofe de dez versos, num sistema de rimas ABBAACCDDC, no folheto Os bichos que falavam, de autoria de João Martins Ataíde (1880-1959):

Vi um mosquito valente (A) promotor advogado, (B) com um pilotão formado, (B) do batalhão tiradente (A) a moriçoca na frente (A) dizendo a cabra não pode $(\mathrm{C})$ depois amarrou o bode (C) que estava no campo nú, (D) mandou prender o muçu, (D) per ter raspado o bigode $(\mathrm{C})^{10}$

Em que pesem as dificuldades classificatórias que os folhetos de cordel impõem aos seus pesquisadores e historiadores, Marlyse Meyer sugere uma possível divisão para se pensar suas formas tão variadas de um modo mais didático. A primeira grande divisão se dá pelas obras de maior extensão e as obras de menor extensão. Com isso, teríamos obras em versos denominadas romances, com textos que variam entre 24, 32, 48 e 63 páginas, e as obras mais conhecidas como folhetos, cujas extensões mais comuns variam entre 8 e 16 páginas ${ }^{11}$. Vejamos a subdivisão de cada uma delas.

Internamente, o romance pode ter muitas subdivisões classificatórias segundo os seus temas abordados. Marlyse Meyer o categoriza da seguinte maneira: 1) romances baseados em temas e histórias da tradição popular. São romances que tratam desde histórias, por assim dizer, mais fantásticas, com monstros, príncipes e reinos encantados até romances com animais que falam e se gesticulam a exemplo dos humanos. Ainda se incluem nessa categoria os romances de tradição religiosa, os romances de anti-heróis, caso de personagens como João Grilo e Pedro Malasartes, e os romances de valentia com personagens adaptados ao cenário nordestino com um grau de heroísmo e de regeneração. 2) Romances ditos de amor, cuja matéria pode ser variada com histórias de
9.FERREIRA, Jerusa Pires. Cavalaria em cordel: o passo das águas mortas. São Paulo: Edusp, 2016. p. 43

10.ATAÍDE, João Martins de. Os bichos que falavam. Editado por José Bernardo da Silva. [S.I.]: [s.n.], [19--?]. p. 2. Intervenções nossas. 11.MEYER, op. cit., p. 97. 
12.MEYER, op. cit., p. 97-98.

13.Ibidem, p. 98-99.

14.Ibidem, p. 99.

15.Ibidem, p. 99-100.

16. Os exemplos de folhetos de cordel, em edições aqui reproduzidas, fazem parte do acervo de cordel da Fundação Casa de Rui Barbosa (FCRB). Sempre que possível, dadas as condições materiais dos folhetos, fizemos a opção de realizar as citações parciais ou completas dos poemas a partir das reproduções de edições originais, as mais antigas possíveis e disponíveis, para que assim se possa ter uma dimensão mais justa dos aspectos não verbais presentes nos folhetos de cordel. Neste caso específico, a edição a ser citada adiante é a seguinte: LIMA Silvino Pirauá de. Desafio de Zé Duda com Silvino Pirauá, descrevendo os reinos da natureza. Belém: Guajarina, 1937. Abiblioteca da FCRB possui mais de 9 mil folhetos sob sua guarda, sendo que 2340 folhetos podem ser consultados digitalmente. Disponível em: http://www.casaruibarbosa. gov.br/cordel/acervo.html Acesso em: jul. 2019.

17.Ver: MAXADO, Franklin Cordel: xilogravura e ilustrações. Rio de Janeiro: Codecri, 1982. separações e encontros e tragédias amorosas que podem resultar em mortes. 3) Os ditos romances de sofrimento, onde quase sempre se narram os infortúnios de uma personagem protagonista. Muitos desses romances de sofrimento eram absorções de histórias presentes em romances de folhetim franceses ${ }^{12}$.

Quanto à categoria dos folhetos, Meyer subdivide-os em três grupos: 1) os de pelejas e de discussões, que podem ser reproduções da memória de disputas entre cantadores, algumas delas celebradas pelo público sertanejo ou diálogos poéticos inventados pelos autores. As discussões, segundo Meyer, é uma espécie de "paródia da peleja", cuja base é a reprodução de "um debate entre duas partes, com diferentes opiniões ou visões de mundo"13. 2) Os folhetos de acontecido: como o próprio nome revela, são as poesias que relatam o cotidiano dos vários sujeitos nordestinos - sua vida, suas agruras, sua religiosidade, seu misticismo, sua força e seu enfrentamento diante das intempéries da natureza. De acordo com Meyer, "os assuntos em geral dos folhetos de acontecido são tratados numa perspectiva realista ou satírica, profética ou moralizadora, ao mesmo tempo em que reproduzem o sistema de valores do homem nordestino"14. 3) Os folhetos de época (ou folhetos de ocasião): são aquelas poesias que tratam de assunto noticiado no jornalismo diário. Este pode ser desde um desastre natural até a morte de uma liderança política ou de uma liderança religiosa, entre tantos outros acontecimentos possíveis ${ }^{15}$.

\section{POETAS POPULARES: TRÊS MESTRES DA PRIMEIRA GERAÇÃO}

Abordaremos agora, de maneira sucinta, a vida e obra de três autores da primeira geração de poetas populares brasileiros que publicaram suas composições na forma de folhetos.

\section{Silvino Pirauá de Lima (1848-1913)}

Responsável por muitas inovações à forma poética dos folhetos, Silvino Pirauá de Lima foi considerado um dos primeiros poetas dessa tradição, assim como o introdutor da forma de romance em versos com histórias mais alongadas. Como forma de exemplificação, cabe um poema bastante curioso de sua autoria. Trata-se de uma peleja, cujo folheto pode ser tanto o registro de memória de um desafio ocorrido como pode ter sido uma peleja resultante da imaginação do seu autor. O título é Desafio de Zé Duda com Silvino Pirauá, descrevendo os Reinos da Natureza.

Vejamos, primeiramente, a capa ${ }^{16}$ desta obra (Figura 1). Os folhetos quase sempre contêm ilustrações sobre o enredo; faz parte do formato dos folhetos o uso de gravuras tanto nas capas como em meio às histórias. Não é exagero dizer que o desenvolvimento da xilogravura no nordeste brasileiro se confunde com as próprias transformações do formato e do gênero dos folhetos de $\operatorname{cordel}^{17}$. 


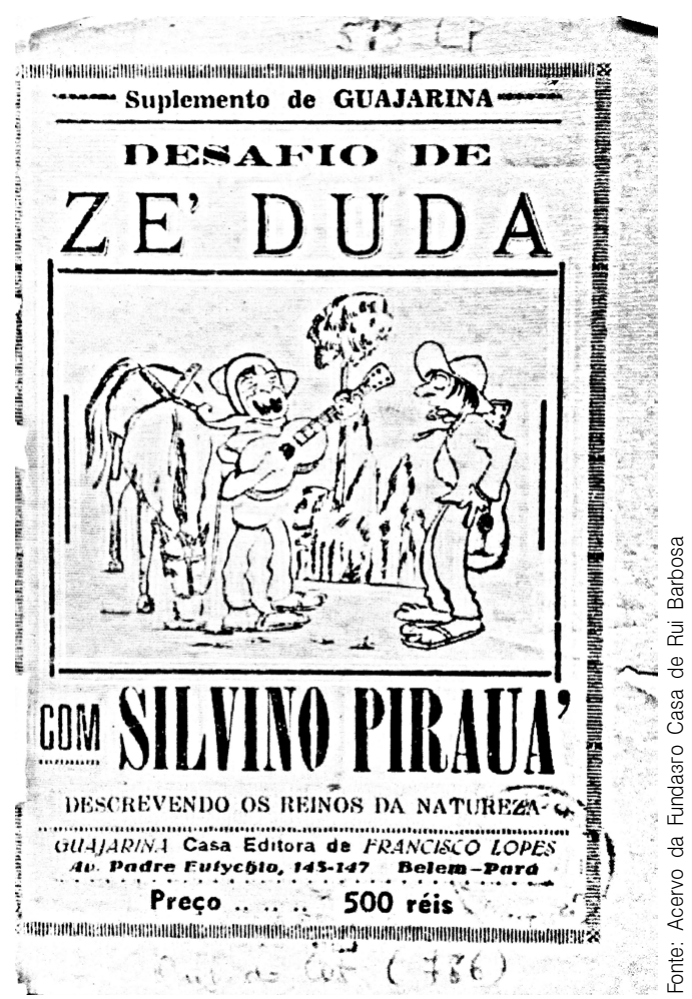

Figura 1: capa de livro de Silvino Pirauá de Lima

E seguem ainda as duas primeiras páginas (Figura 2 ):

S.-Zé Duda á sua pergunta resposta clara vou dar: - Fui morador do sertão

venho na praça morar,

pretendo aqui viver bem, nào quero me desgraçar

Z.-Pirauá, quem the mandou entrar em meu Pernambuco? Ignoravas talvez

de que sou cantor de succo?

Agora o seu resultado

e ficar doido ou maluco !

S.- Eu náo venho aqui mandado

desde já fique sabendo,

o senhor tem nuito succo

porém a si năo ne rendo,

pretende deixar-me doido

mas isso eu só creio vendo.

Z. - Me informaram que voce era eximio cantador.

que da arte que ora exerce

pretende ser professor

que em sciencia pratica

- discute como um doutor.

S-Zé Duda, ha mais de 30 annos que eu vivo de cantoria

năo me julgo mais que os outros
I

DESAFIO

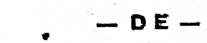

Zé Duda COM

Silvino Pirauá

Descrevendo os Reinos da Natureza

Preste attenção, meu leitor, ao caso que vou contar d'um desafio intrincado que custou em se acabar, todos dois era:n valentes em saber desafiar.

Zé Duda foi o primeiro que o silencio toi rompendo mas logo a sua pergunta Pirauá vae respondendo. por isso, muita attenç que já éstão se debaitendo.

Ze-Senhor Silvino é preciso que una pergunta lie faça: -Voce mora no serta

Tera vindo ao Recife buscar a sua desgraça



Figuras 2: primeira e segunda páginas do livro de Silvino Pirauá de Lima 
Pode-se notar que todo o poema é construído em estrofe de seis versos. Sua rima é denominada ABCBDB: o segundo verso rima com o quarto e com o sexto versos; os demais versos são soltos dentro do poema. De um ponto de vista estrutural e temático, já a partir da página três (Figura 3), a peleja se encaminha para os desafios dos testes científicos entre os adversários, como se pode notar:

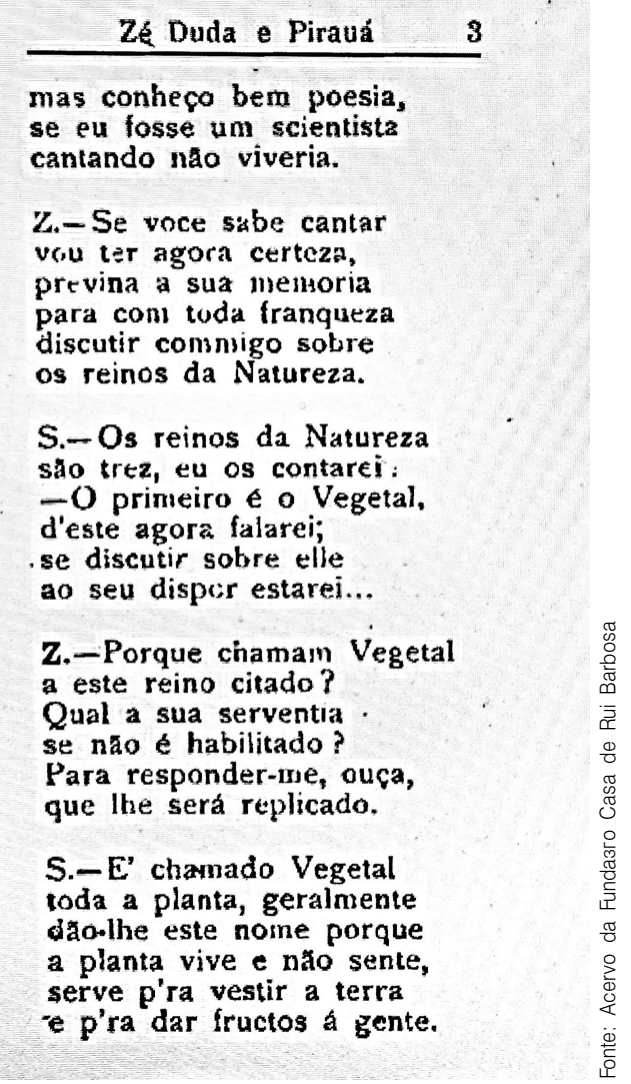

Figura 3: página três do livro de Silvino Pirauá de Lima

São longas páginas em que os pelejadores desafiam uns aos outros por meio de perguntas e enigmas sobre o conhecimento dos reinos da natureza, algo bastante comum em muitos desafios presentes nos folhetos. Como é sabido, essa forma narrativa do desafio terminava com algumas condições: quando um dos desafiantes se mostrava superior, imputando ao outro uma pergunta que deixava o adversário sem reação e resposta; quando os desafiantes se desentendiam de tal maneira que a peleja não poderia mais prosseguir; ou ainda quando os pelejadores reconheciam a força de seus adversários e, amistosamente, punham fim à disputa. Este é o caso em questão (Figura 4): 


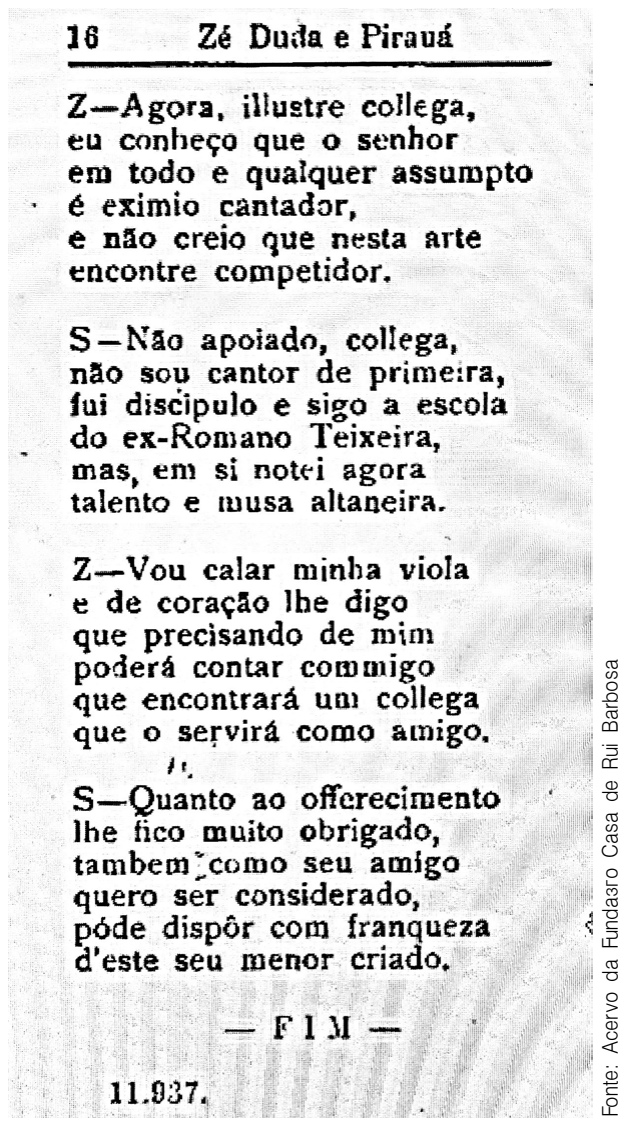

Figura 4: página 16 do livro de Silvino Pirauá de Lima

\section{Leandro Gomes de Barros (1865-1918)}

Dois motivos levaram o poeta Leandro Gomes de Barros a ganhar relevância na história da literatura de folhetos: 1) a sua própria produção de poemas, que ajudou a fixar as normas, os temas de recorrência e o gênero de composição textual desse tipo de poesia popular; 2) a sua atuação como editor e impressor de folhetos que impulsionou a atividade de outros poetas populares.

Crítico e historiadores do cordel são unânimes em afirmar a importância de Leandro Gomes de Barros em relação a essas duas atividades em fins do século XIX, datando de 1893 o seu folheto mais antigo. Desta época até o final dos anos 1920, seguindo a empreitada de Leandro Gomes de Barros, houve um período no qual cerca de mais de vinte autores realizaram a publicação de seus trabalhos de poesia popular na forma impressa dos folhetos.

Para que se tenha uma ideia do talento poético de Leandro Gomes de Barros, veja-se um dos seus poemas denominado "O fiscal e a lagarta" (Figura 5), com data atribuída de $1917^{18}$ : 
O FISCAL E A LAGARTA

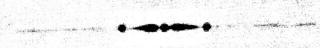

Estava um dia uma lagarta

Debaixo de um pé de fumo

Quando levantou a vista

Viu um fiscal do consummo,

Disse a lagarta comsigo:

Eu hoje me desarrumo.

O fiscal perguntou logo

Insecto, o que estás roendo?

A lagarta perguntou-lhe

Fiscal, que andas fazendo?

- Aperriando o commercio

Tomando tudo e comeado.

Disse o fiscal: para imposto.

$O$ governo me nomeia,

A lagarta respondeu-Ihe

Você precisa é cadeia.

Para perder o costume

De andar roubando de meia

Disse o fiscal: o governo

Nào puderá se manter,

Sem procurar o imposto

De quem comprar e vender.

Artista e agricultor

Pagam por justo dever.

\section{$-B-$}

Disse a lagarta: o governo

Não podia trabalhar?

Deixar de ser sanguessuga,

$O$ sangue humano chupar.

Eille plante canna e fumo

Se quer beber e fumar!

Bota um pobre uma bodéga

Alem de veüder fiado,

Quando vê bater-lhe á porta

Un dragão engravatado,

Com o bucho muito grande

Fi o bigode raspado.

Emboca de casa a dentro

Vai logo cascaviar,

$\mathrm{N}$ ão pede ao lono da casa

A licença para entrar.

E' igualmente ao cachorro

Entra sem uinguem mandar.

O fiscal disse: ę você

Acha que faz pouco tamno?

I)isse a logarta: en conhesso.

Que sou inseto tyranuo

Porém, sí venho uma vez

- Vote rem muitas no anno.

F: ha de tratal-o tem

Com bôa dormida e ceia

Se vão the nostrar carinho

I) ficer-lhe cara feia,

$O$ cobre vai para o cofre

E o dono para a cadeia.

Figura 5: reprodução de "O fiscal e a lagarta"

Trata-se de um poema que está localizado na tradição da celebração de animais, que, com base no humor e na sátira, criam maneiras de refletir sobre o mundo dos seres humanos. No enredo da narrativa, uma lagarta confrontar um fiscal representante do Estado é, por si só, uma espécie de ridicularização de uma situação cotidiana de alta crítica política. O poema, criado em estrofes de seis versos, tematiza algo que parecia muito caro aos sertanejos: a distância do Estado e suas formas de controle. Por estrofes, cheias de humor e ironia, a personagem Lagarta domina o tom e revela, por uma perspectiva singular, as faces de um Estado negligente com o cidadão do sertão nordestino em muitos momentos.

Um de seus poemas mais conhecidos é $O$ boi misterioso, também publicado como A história do boi misterioso. Certamente, trata-se da sua obra mais reimpressa, sendo responsável por inaugurar uma espécie de "ciclo do boi na poesia popular"19. O registro dessa história está ligado ao imaginário de muitas narrativas que os sertanejos compartilhavam em torno de bois, sobretudo de animais que fogem e depois precisam ser perseguidos e capturados. A história narra um evento que pode ter ocorrido em 1825 no sertão da Paraíba e é um

19.Ver: HAURÉLIO, Marco. Breve história da literatura de cordel. São Paulo: Claridade, 2016. tanto curiosa. Seu roteiro parte de um boi, ainda jovem e rebelde, que foge por longos anos das vistas dos vaqueiros. É dessa maneira que Leandro Gomes de Barros inicia suas primeiras estrofes: 
Leitor, vou narrar um fato dum boi da antiguidade como não se viu mais outro até a atualidade aparecendo um desses hoje era grande novidade

Durou vinte e quatro anos nunca ninguém o pegou vaqueiro que tinha fama foi atrás dele, chocou cavalo bom e bonito foi lá, porém estancou ${ }^{20}$

A história começa a se desenvolver a partir da própria caracterização do boi, afinal,

Ele nunca achou riacho que dum pulo não saltasse e nunca formou carreira que com 3 léguas cansasse como nunca achou vaqueiro que em sua cauda pegasse.

Muitos cavalos de estima atrás dele se acabaram vaqueiros que em todos campos até medalhas ganharam muitos venderam os cavalos, e nunca mais campearam ${ }^{21}$

O mistério se inicia quando novos personagens são atraídos para o enredo e fenômenos sobrenaturais começam a dar dinâmica à história e, por conseguinte, ao mistério. Um dos vaqueiros da comunidade caçava uma onça quando viu o que parecia ser algo de outro mundo:

$\mathrm{O}$ vaqueiro viu que os vultos eram de duas mulheres uma delas disse à vaca: partes por onde quiseres eu protegerei a ti e as filhos que tiveres

Aí o vaqueiro viu um touro ali chegar então disseram os vultos: é hora de regressar; disse o touro: montem em mim que o galo já vai cantar ${ }^{22}$

Será dessa mesma vaca avistada pelo vaqueiro que nascerá o boi misterioso. É um animal que não se deixa pegar pelos vaqueiros. Mesmo os mais vitoriosos

20.BARROS, Leandro Gomes de. História do boi misterioso. Editado por José Bernardo da Silva. Juazeiro do Norte: Tipografia São Francisco, [19--?]. p. 1. A autoria deste texto é atribuída a Leandro Gomes de Barros devido ao apócrifo presente na última estrofe do poema.

21.Ibidem, p. 2.

22.lbidem, p. 3-4. 
não conseguem trazer de volta o boi, como é o caso do vaqueiro que chega de Minas Gerais especialmente para a captura do boi misterioso e cuja voz o poema registra o seguinte:

- Nunca vi bicho correr

com tanta velocidade

só lampejo de relâmpago

em noite de tempestade

nem peixe nágua se move

com tanta facilidade! ${ }^{23}$

Depois de muitos desencontros e tentativas malogradas de captura do boi misterioso, a narrativa desemboca em seu final, o que parece ser a última tentativa de encontrá-lo. Entre os vaqueiros, um deles vindo de Mato Grosso parecia ser diferente, conforme disse o coronel: "se houver diabo aquele é um certamente". Nas cenas finais, inicia-se a perseguição entre o tal vaqueiro e o boi misterioso, cujo desfecho se dá em chave cheia de suspense e de mais mistério:

Bem no centro da campina

havia uma velha estrada

feita por gado dali

porém já estava apagada

depois com outra vereda

fazia um encruzilhada

Iam o vaqueiro e o boi

pela dita cruz passar

ali enguiçava a cruz

ou tinha então de voltar

devido aos outros vaqueiros

não havia outro lugar

Mas o boi chegando perto

não quis enguiçar a cruz

tudo desapareceu

ficou um foco de luz

e depois dela saíram

uma águia e dois urubus

Tudo ali observou

o fato como se deu

viu-se que o chão se abriu

e o campo estremeceu

pela abertura da terra

viram quando o boi desceu

Voltaram todos os vaqueiros o coronel constrangido pelo boi e o tal vaqueiro terem desaparecido a terra abriu-se e fechou-se pôs tudo surpreendido ${ }^{24}$ 


\section{João Melquíades Ferreira da Silva (1869-1933)}

Certamente, João Melquíades Ferreira da Silva é um dos grandes poetas da primeira geração de autores de folhetos de cordel. Ele publicou uma obra numerosa, explorando diversos temas e tipos de folhetos. Era também um cantador e apresentava-se no sertão em companhia de outros cantadores, em especial, José Camelo de Rezende e Romano Elias da Paz ${ }^{25}$.

Sem dúvida, um de seus folhetos mais difundidos é $O$ romance do pavão misterioso. Em torno dele, há uma controversa sobre sua autoria. Segundo versão de José Camelo, José Melquíades teria plagiada a obra a partir de um original deixado por Camelo com Romano Elias da Paz. A versão de Camelo, publicada tempos depois daquela de Melquíades, atesta uma diferença bastante visível entre as obras e coloca mais dúvida sobre o que, realmente, possa ter ocorrido.

Ainda jovem, João Melquíades ingressou no exército, tendo sido um dos combatentes em Canudos. Desta guerra, o poeta traz a matéria para a produção de seus folhetos em torno desse confronto de fins do século XIX ${ }^{26}$, conforme veremos a seguir. Comecemos pela imagem da capa do folheto A Guerra de Canudos $^{27}$ (Figura 6):

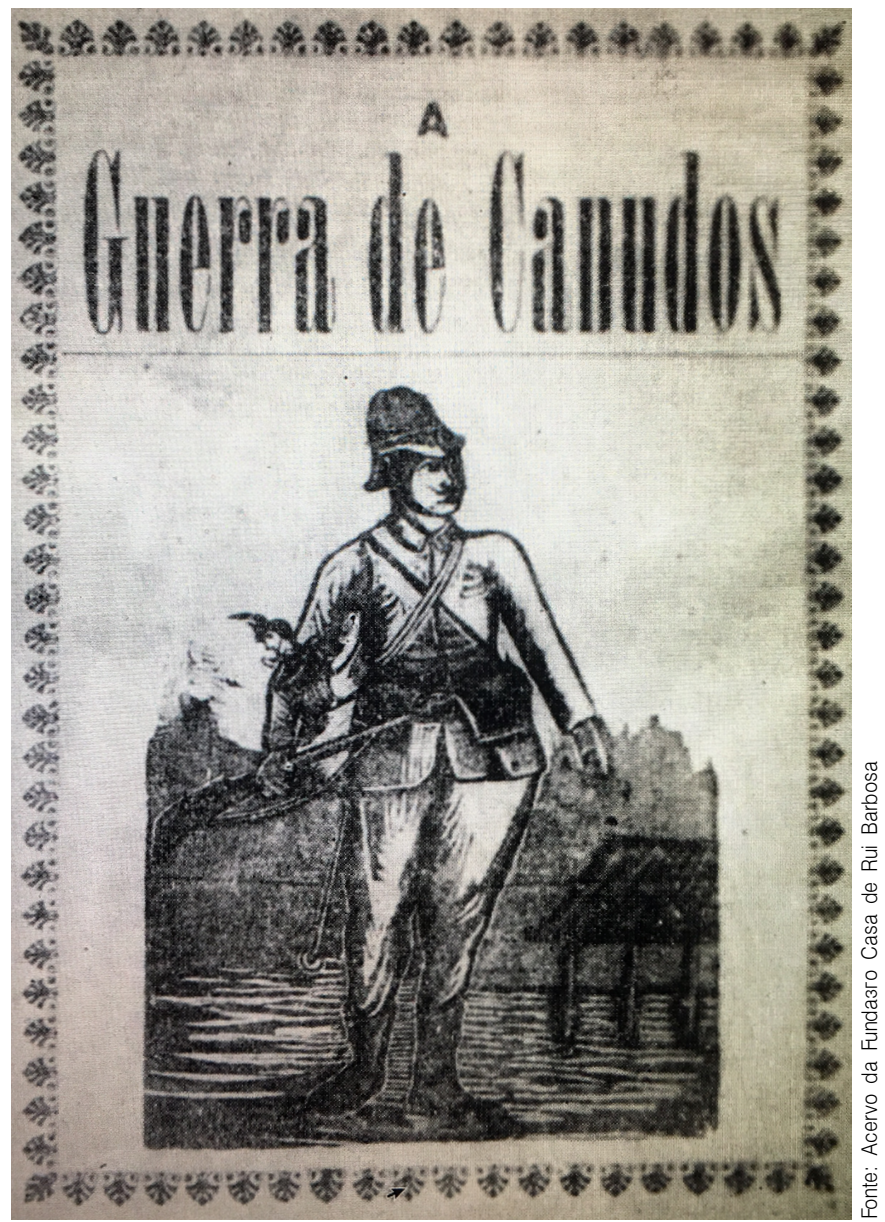

Figura 6: capa de A Guerra de Canudos
25.ABREU, Márcia. Antologia de folhetos de cordel: amor, história e luta. São Paulo: Moderna, 2005. p. 46.

26.Sobre a representação de Canudos nos folhetos de cordel, ver o estudo: CALASANS, José. Canudos na literatura de cordel. São Paulo: Ática, 1984.

27. Cabe esclarecer que o achado deste poema e a atribuição de autoria a José Melquíades são fruto das pesquisas do historiador José Calasans em torno da Guerra de Canudos. O poema, na íntegra está publicado pelo historiador em: SILVA, José Melquíades Ferreira da. A Guerra de Canudos. In: CALASANS, José. 'A Guerra de Canudos'. Revista Brasileira da Folclore. Rio de Janeiro, v. 6, n. 14, p. 57-63, jan./abr. 1966. 
Como já foi dito antes, os folhetos de acontecido é um gênero bastante comum entre os poetas. Em A Guerra de Canudos, José Melquíades se dedicou a este tipo de folheto. Suas primeiras estrofes são as seguintes:

No ano noventa e seis

O Exército brasileiro

Achou-se então comandado

Pelo general guerreiro

De nome Arthur Oscar

Contra um chefe cangaceiro

Ergueu-se contra a República

$\mathrm{O}$ bandido mais cruel

Iludindo um grande povo

Com a doutrina infiel

Seu nome era Antônio

Vicente Mendes Maciel.

Por causa deste bandido

Ter a mão assassinada

Fugiu de Aracaty

Do Ceará seu Estado

Vestia-se como frade

Se conservando barbado.

De alpercatas, um cajado

Armado de valentia

Seu pensamento era o crime

Outra coisa não queria

Agradou-se de Canudos

Que é sertão da Bahia.

E para iludir ao povo

Ignorante do sertão

Inventou fazer milagres

Dizia em seu sermão

Que virava a água em leite

Convertia pedra em pão.

Criou-se logo em Canudos

Um batalhão quadrilheiro

Para exercitar os crimes

Desse chefe canganceiro

Então lhe deram três nomes

De Bom Jesus Conselheiro ${ }^{28}$.

28.SILVA, José Melquíades Ferreira da. A Guerra de Canudos. In: CALASANS, José. 'A Guerra de Canudos'. Revista Brasileira da Folclore. Rio de Janeiro, v. 6, n. 14, jan./abr. 1966, p. 58.
Diferente de Euclides da Cunha de Os Sertões (1902), que enuncia em seu livro mais de uma vez a força do homem sertanejo, é interessante notar o ponto de vista na narrativa de José Melquíades. Este parece reiterar um ponto de vista comum à época: o de que Canudos foi tão somente um movimento de fanáticos religiosos. É preciso talvez compreender as circunstâncias pelas quais Melquíades experienciou para melhor aprofundar a leitura. Como soldado 
que participou da guerra, talvez ainda estivesse sob forte impacto do calor da guerra e, assim, suas interpretações estariam mais sujeitas a aceitarem a versão oficial sobre o conflito. Em outra passagem, o ponto de vista dos republicanos do litoral se reitera, sobrepondo-se ao dos resistentes de Canudos:

Fomos chorar pelos mortos

Companheiros veteranos

Morreu cinco comandantes

E o major Severiano

Mais de cinco mil homens

Ficou no solo baiano.

Foi desmanchada a cidade

Toda telha se quebrou

Derrubamos as Igrejas

A madeira se queimou

A cidade criminosa

Como tapera ficou ${ }^{29}$.

Ainda sobre o tema da Guerra, Melquíades publicou também um poema sobre a I Guerra Mundial. Intitula-se A vitória dos aliados: a derrota da Alemanha e a influenza espanhola (1918). Depois de narrar muitos momentos de tensão e negociação entre aliados e os chamados Impérios Centrais (Alemanha e Áustria-Hungria) no complexo conflito da I Guerra Mundial, vejamos como o autor dá um desfecho ao conflito ${ }^{30}$ (Figura 7):



Figura 7: última página de $A$ vitória dos aliados 
Como este texto é uma breve introdução/apresentação da poesia popular de folhetos, cabem algumas palavras finais sobre as fontes de pesquisa e repositórios digitais de clássicos da nossa poesia em folhetos de cordel. Quem se interessar poderá encontrar muitos folhetos de cordel digitalizados e bem catalogados em instituições que mantém um espaço relevante para a pesquisa dessa temática.

Entre muitas possibilidades, focalizo algumas instituições importantes.

É o caso da Fundação Casa de Rui Barbosa, que mantém o Acervo de Literatura Popular em Versos com um projeto de restauro e digitalização de um dos mais importantes materiais documentais sobre o cordel no Brasil ${ }^{31}$.

A Fundação Joaquim Nabuco também possui um acervo de folhetos. O número de folhetos é em menor número que a FCRB, porém há alguns bastante raros $^{32}$.

O Centro Nacional de Folclore e Cultura Popular é uma instituição ligada ao Instituto do Patrimônio Histórico e Artístico Nacional (IPHAN) e possui também um acervo de folhetos ${ }^{33}$.

Fora do Brasil, um dos principais acervos no tema é o da Universidade de Poitiers, na França, com o Acervo Raymond Cantel. Consta que fazem a guarda de aproximadamente 4 mil folhetos, das quais algumas são obras raras digitalizadas ${ }^{34}$.

31.Pessoas interessadas podem ter acesso ao acervo digitalizado e outras informações de referência sobre o assunto em: http://www. casaruibarbosa.gov.br/ cordel/apresentacao.html Acesso em: 4 out. 2020.

32.Disponível em: https:// www.fundaj.gov.br/images/ stories/biblioteca/inventarios/CordelAcervoFundaj2008.pdf. Acesso em 7 out. 2020.

33.Podem ser acessados em: http://www.cnfcp. gov.br/interna.php?ID_ Secao $=65$. Acesso em: 4 out. 2020 .

34.As obras podem ser consultadas em: http://cordel. edel.univ-poitiers.fr/. Acesso em: 4 out. 2020.

\section{REFERÊNCIAS BIBLIOGRÁFICAS}

ABREU, Márcia. Antologia de folhetos de cordel: amor, história e luta. São Paulo: Moderna, 2005.

ABREU, Márcia. Histórias de cordéis e folhetos. Campinas: Mercado de Letras, 1999.

ATAÍDE, João Martins de. Os bichos que falavam. Editado por José Bernardo da Silva. [S.l.]: [s.n.], [19-?].

BARROS, Leandro Gomes de. História do boi misterioso. Editado por José Bernardo da Silva. Juazeiro do Norte: Tipografia São Francisco, [19-?].

BARROS, Leandro Gomes de. O fiscal e a lagarta. Recife?: [s.n.], 1917?.

CALASANS, José. Canudos na literatura de cordel. São Paulo: Ática, 1984.

CANDIDO, Antonio. A literatura e a formação do homem. In: CANDIDO, Antonio. Textos de intervenção. Apresentações e notas de Vinicius Dantas. São Paulo: Duas Cidades: Editora 34. p. 77-92.

FERREIRA, Jerusa Pires. Cavalaria em cordel: o passo das águas mortas. São Paulo: Edusp, 2016.

HAURÉLIO, Marco. Breve história da literatura de cordel. São Paulo: Claridade, 2016. 
LIMA, Silvino Pirauá de. Desafio de Zé Duda com Silvino Pirauá, descrevendo os reinos da natureza. Belém: Guajarina, 1937.

MAXADO, Franklin. Cordel: xilogravura e ilustrações. Rio de Janeiro: Codecri, 1982.

MEYER, Marlyse. Muitas histórias, muita poesia... In: MEYER, Marlyse (org.). Autores de cordel. São Paulo: Abril Educação, 1980. p. 3-5.

ROCHA, Glauber. Deus e o Diabo na Terra do Sol. Rio de Janeiro: Civilização Brasileira, 1965.

SILVA, João Melchiades Ferreira da. A victoria dos alliados: a derrota da Allemanha e a influenza hespanhola. Parahyba: Popular, 1918.

SILVA, José Melquíades Ferreira da. A Guerra de Canudos. In: CALASANS, José. "A Guerra de Canudos". Revista Brasileira da Folclore, Rio de Janeiro, v. 6, n. 14 , p. 57-63, 1966. 